\title{
Total cavopulmonary connection with a new bioabsorbable vascular graft: First clinical experience
}

\author{
Leo A. Bockeria, MD, ${ }^{a}$ Oleg Svanidze, MD, ${ }^{b}$ Alex Kim, MD, ${ }^{a}$ Konstantin Shatalov, MD, \\ Vladimir Makarenko, MD, ${ }^{\mathrm{a}}$ Martijn Cox, $\mathrm{PhD},{ }^{\mathrm{b}}$ and Thierry Carrel, $\mathrm{MD}$
}

\begin{abstract}
Objectives: To assess safety and clinical performance of a novel bioabsorbable vascular graft in pediatric patients with univentricular cardiac malformation who received surgical correction via an extracardiac cavopulmonary conduit.

Methods: The implanted graft material is designed to attract patient's own cells and proteins, which trigger a cascade of physiological events leading to endogenous tissue restoration. As the graft resorbs progressively after implantation, components of native tissue including collagen, endothelial lining, and capillary blood vessels develop and organize into a natural tissue. Five patients (aged 4-12 years) received this new vascular graft as interposition between the inferior vena cava and the pulmonary artery. They were followed up to 12 months after surgery. The conduit was assessed by echocardiography, computed tomography and magnetic resonance imaging, including 4-dimensional flow.
\end{abstract}

Results: All patients recovered from the procedure without complications. No device-related adverse events were reported. Two patients required interventional occlusion of aortopulmonary collaterals. At 12 months, there was a significant improvement in the patients' general condition. Imaging studies demonstrated anatomical (conduit diameter, length and wall thickness) and functional (blood flow pattern) stability of the bioabsorbable grafts in all patients with no significant changes at 12 months compared with early postoperative data.

Conclusions: Initial clinical experience with a novel absorbable graft underlines the potential of this new material to improve cardiac and vascular surgical procedures. In addition, better biocompatibility may reduce permanent implant-related complications. A longer follow-up is needed to assess the long-term effectiveness of biodegradable vascular grafts, including their ability to grow. (J Thorac Cardiovasc Surg 2017;153:1542-50)

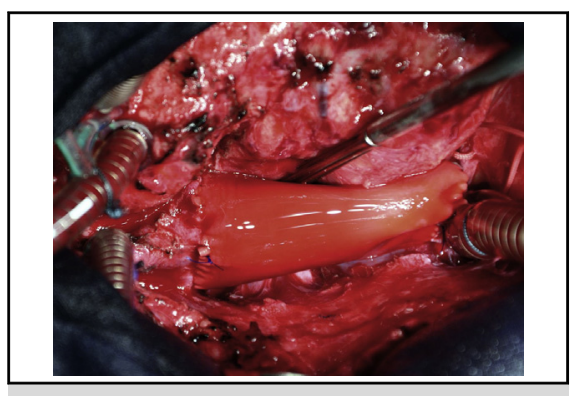

Intraoperative view of the vascular graft implanted between the inferior vena cava and the right pulmonary artery.

\section{Central Message}

This new technology has the potential to improve cardiac and vascular surgical procedures because it will reduce implant-related complications.

\section{Perspective}

The bioabsorbable vascular graft is easy to handle. Imaging studies demonstrated anatomical (conduit diameter and wall thickness) and functional (blood flow pattern) stability of the graft in the 5 patients with no significant changes at 12 months compared with early postoperative data.

See Editorial Commentary page 1551.
The number of newborns who suffer from life-threatening complex congenital heart disease and require cardiac surgery is approximately 100,000 per year worldwide. ${ }^{1-3}$ The use of artificial grafts, homografts, or xenografts is

From the a Department of Cardiovascular Surgery, Bakulev Center, Moscow, Russia; ${ }^{b}$ Xeltis BV, Eindhoven, The Netherlands; and ${ }^{c}$ Department of Cardiovascular Surgery, University of Bern, Bern, Switzerland.

This clinical study was sponsored by Xeltis AG, and all payments were made to the hospital. The authors attest that they had full freedom to explore the data and analyze the results independently from the sponsor and that they had sole authority to make the final decision to submit the material for publication.

Received for publication June 23, 2016; revisions received Nov 6, 2016; accepted for publication Nov 27, 2016; available ahead of print March 14, 2017.

Address for reprints: Leo A. Bockeria, MD, Department of Cardiovascular Surgery, Bakulev Scientific Center, Moscow, Russia (E-mail: leoan@bakulev.ru). 0022-5223/\$36.00

Copyright (c) 2017 by The American Association for Thoracic Surgery

http://dx.doi.org/10.1016/j.jtcvs.2016.11.071 standard of care to repair congenital malformations. ${ }^{4-7}$ These materials, however, typically are associated with adverse events, including rejection, chronic infection, stenosis, thromboembolic events, and calcifications. ${ }^{8-13}$ In addition, the current available materials are unable to grow; this means that these younger patients often require repeat surgery. ${ }^{14,15}$ To overcome these limitations, a new generation of vascular graft has been developed that is

Scanning this QR code will take you to a supplemental video for the article. To view the AATS 2016 Webcast, see the URL next to the video thumbnail.

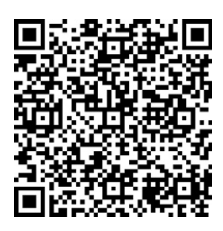




\section{Abbreviations and Acronyms \\ 4D = 4-dimensional \\ MRI = magnetic resonance imaging \\ $\mathrm{PTFE}=$ polytetrafluoroethylene}

based on a bioabsorbable polymer matrix designed to induce autologous repair by endogenous tissue restoration, a spontaneously growing, natural, healthy tissue with cells contributed only from the recipient. Immediately after the implantation, the prosthesis is functional but with time, neotissue is formed and organizes into a fully functional blood vessel while the polymer gradually is bioresorbed.

This approach is not completely new: as early as 2001 Shinoka and Breuer developed the idea that optimal filling materials with biocompatibility and growth potential may have significant advantages for pediatric patients in whom foreign material has to be implanted as part of the reconstructive procedure. ${ }^{16,17}$ They reported the advantages of tissue-engineered vascular autografts in models in animals and in human clinical applications by using autologous cells and biodegradable scaffolds. The key benefit from the use of such scaffolds is that they degrade in vivo, thereby avoiding the long-term presence of foreign materials because the seeded cells proliferate and differentiate to construct new tissue. More recently, they have developed the same concept for small-caliber vascular grafts. ${ }^{18,19}$

\section{METHODS}

The vascular graft is a sterile, flexible, straight, highly porous conduit composed of a bioresorbable supramolecular polyester ${ }^{20}$ and processed by electrospinning. The polyester is obtained by chain-extending poly-caprolactone with 2-ureido- $4[1 \mathrm{H}]$-pyrimidinone. The 2-ureido-4 $[1 \mathrm{H}]$-pyrimidinone motif is self-complementary by forming quadruple hydrogen bonding; this leads to a significant improvement in mechanical properties while still allowing the material to be processed. ${ }^{21}$ Scanning electron microscopy shows that the graft structure is made up of a scaffold of fibers (Figure 1). The graft matrix is flexible and strong enough to support the pressure of the cardiovascular system with a porous environment that allows and stimulates cell penetration and subsequent tissue growth, without the use of stem cells, growth factors, or animal-derived products.
Standard biocompatibility tests were performed in Good Laboratory Practices-certified laboratories according to ISO-10993. Tests included cytotoxicity, genotoxicity, pyrogenicity, and several others. All tests were passed.

A prospective first in human, clinical investigation was performed in a single center, the Bakulev Center for Cardiovascular Surgery, Moscow, Russian Federation (Clinicaltrials.gov number, NCT02377674). The new vascular graft (Xeltis AG, Zurich, Switzerland) was implanted in 5 pediatric patients aged 4 to 12 years over a recruitment period of 5 months (October 2013 to February 2014).

Ethics committee approval was gained before we began the study, and all consent forms were signed by the relatives before enrollment. The new vascular graft was implanted during the second step of a modified Fontan procedure as an extracardiac total cavopulmonary connection and therefore connected the inferior vena cava with the right pulmonary artery. Surgical technique and graft implantation were performed with the same standard as for other commercially available vascular conduits (synthetic, homograft, or xenograft) (Video 1). The patients were followed with postoperative examinations at discharge and at months 1, 3, 6, 9, and 12 after implantation. Follow-up included documentation of the patients' clinical condition and of all adverse events (related or not to the new implant), information on concomitant medication, and transthoracic echocardiographic assessment.

The data were collected for each follow-up visit and monitored by an independent clinical research assistant to ensure the accuracy of the information. All serious adverse events were reviewed by an independent clinical review committee comprising 1 cardiologist and 2 cardiac surgeons.

\section{RESULTS}

The 5 patients ( 3 male and 2 female) were in average New York Heart Association functional class II at entry to the trial. All patients previously had received a bidirectional cavopulmonary anastomosis (Glenn shunt), 3 a coiling occlusion of aortopulmonary collaterals, and 1 had received a modified Blalock Taussig shunt. The average age was $6.2 \pm 2.9$ years, and the average body mass index was $14.5 \pm 2.1\left(\mathrm{~kg} / \mathrm{m}^{2}\right)$. A summary of the baseline cardiac assessments is shown in Table 1 .

All patients underwent successful graft implantation as the second step of a modified Fontan procedure (Figure 2). Cardiopulmonary bypass time ranged from 83 to 120 minutes. Three patients received a graft of $18 \mathrm{~mm}$ in diameter and 2 received a graft of $20 \mathrm{~mm}$ in diameter. No total cavopulmonary connection was performed with a fenestration. This new graft does not require preclotting, and no blood was observed oozing through the prosthetic
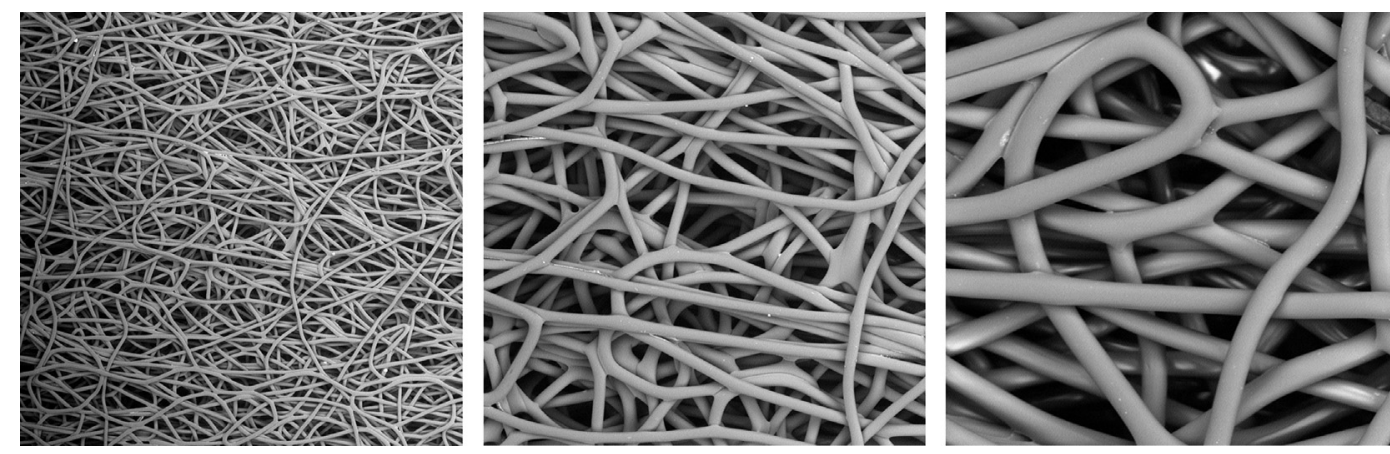

FIGURE 1. Scanning electron microscope images of the graft material at $500 \times, 1500 \times$, and $3500 \times$ magnification. 


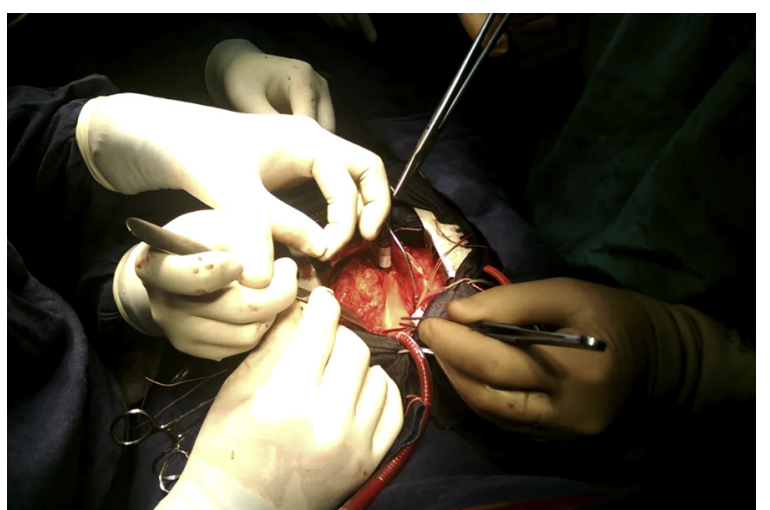

VIDEO 1. An 18 -mm conduit implanted in 4.5 -year-old boy $(16.5 \mathrm{~kg})$. The video shows completion of the anastomosis between the conduit and right pulmonary artery performed with running 5-0 Prolene suture. Video available at: http://www.jtcvsonline.org/article/S0022-5223(17)30163-0/ addons.

material despite full heparinization during cardiopulmonary bypass. Surgeons who performed the operation described the new material as flexible, easy to handle, and easy to suture. There were no intraoperative or postoperative complications.

No graft-related adverse events were observed during the 12-month follow-up period. Two patients with persistent pleural effusions required interventional occlusion of aortopulmonary collaterals. Transthoracic echocardiography was performed at each follow-up visit $(1,6,9$, and 12 months) and demonstrated anatomical stability and optimal function of the extracardiac conduit in all patients. Magnetic resonance imaging (MRI) was performed in 4 patients (in 1 after 9 months and in 3 after 12 months) and 4-dimensional (4D) flow imaging showed that there was laminar flow without turbulence (Figure 3). The fifth patient was unable to complete MRI because of an allergic reaction during the sedation before the examination. 4D flow MRI allowed for a comprehensive evaluation of blood flow patterns using blood flow visualization and flexible retrospective quantification of flow parameters. The mean left ventricular ejection fraction was $53.6 \pm 9.3$ at 6 months and $57.6 \pm 6.1$ at 12 months. Echocardiography allowed us to exclude turbulence or thrombus in the graft.

TABLE 1. Transthoracic echo and angiography values before surgery

\begin{tabular}{lc}
\hline \multicolumn{1}{c}{ Demographics } & $\begin{array}{c}\text { Value } \pm \text { standard deviation } \\
(\mathbf{N}=\mathbf{5})\end{array}$ \\
\hline LVEF & $62.6 \pm 3.3$ \\
Systolic pulmonary artery pressure & $14.8 \pm 2.6$ \\
Diastolic pulmonary artery pressure & $7 \pm 0.9$ \\
Regurgitation AV valve & Minimum to mild \\
Regurgitation outflow valve & None \\
Outflow tract obstruction isthmus & None \\
Outflow tract obstruction aortic arch & None \\
\hline
\end{tabular}

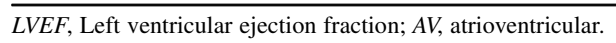

Postoperative diameters and maximal velocities in the graft are summarized in Table 2.

One patient demonstrated an abnormal qualitative assessment of ventricular function that developed at the 6-month visit and was still apparent at 12 months. Three patients received warfarin (because of prolonged immobilization), and 2 patients were treated with aspirin as long-term anticoagulation. Two cardiacrelated adverse events were reported: bundle branch block in one and sick sinus syndrome in another patient, but neither required treatment. Four patients experienced 6 other adverse events: pleural effusions in 3, pneumonia in 1, and Dressler syndrome in 1 whereas 1 patient had significantly reduced function of the systemic ventricle. None of these adverse events was considered as related to the graft.

\section{DISCUSSION}

Preclinical studies in animals (results not shown in detail here) performed with this new graft have demonstrated that the material is well tolerated, initiating a normal tissue response as soon as it is implanted (Figure 4). ${ }^{22}$ These studies in animals have shown promising results in the pulmonary position: 1 year after implantation, the polymer was fully fragmented but not fully resorbed. Histologic examinations showed a bioabsorption process that is still active at this time ${ }^{22}$ Figure 4 provides an overview of the absorption process over time: it shows a gradual replacement of the prosthetic material by autologous neotissue. The implant starts to become fragmented after 6 months and the process continues until 12 months. Contrary to polytetrafluoroethylene (PTFE), there is a very clear absorption occurring, starting with fragmentation of the polymer before it is finally digested by inflammatory cells involved in the process.

Long-term studies in sheep have shown that at 2 months and beyond, the derived burst pressure of the explant (implant + neotissue) is in all cases greater and on average more than twice as high compared with the burst pressure of a bare scaffold implant and compared with a native pulmonary artery. The same study also demonstrated that the implant material has lost its mechanical integrity at 6 months after implantation (the graft is fragmented), indicating that functionality has been taken over completely by the newly formed tissue. ${ }^{22}$

The endogenous tissue restoration process mimics normal tissue regeneration: mild leukocyte infiltration, ingrowth of neointima (lined with endothelium), influx of myofibroblasts, and finally collagen and elastin formation. Histologic examination at 53 weeks after implantation with hematoxylin and eosin staining highlights that there are islands of prosthetic material surrounded by a meshwork of refractile fibers with various giant cells, lymphocytic activity, and the presence of collagen fibers 


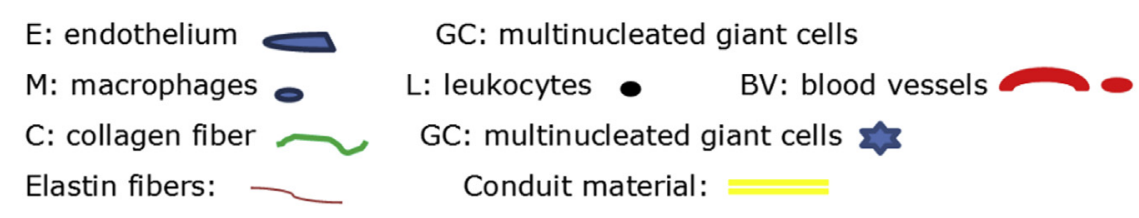

\section{Cell infiltration Tissue formation Graft replacement Graft removal}
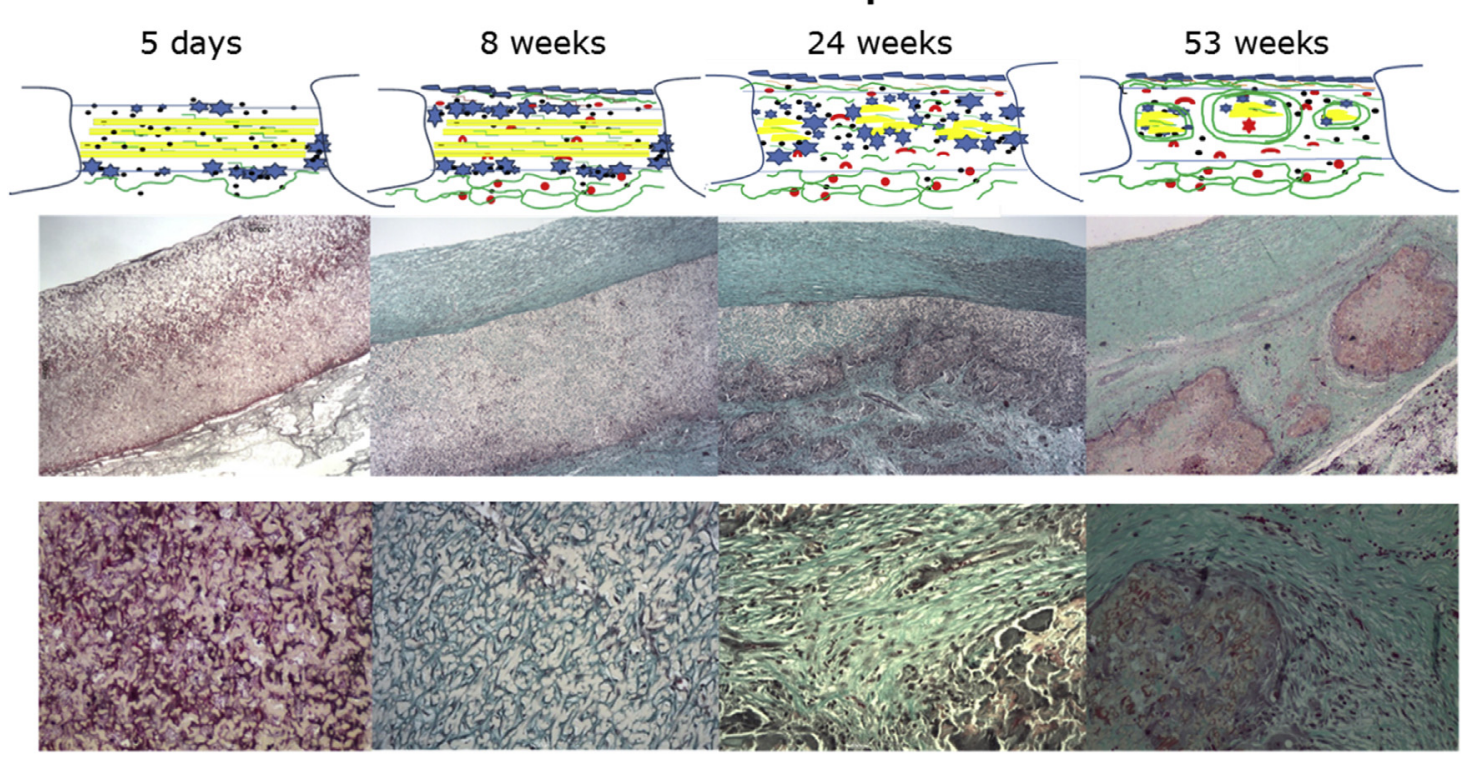

FIGURE 2. Intraoperative site: implantation of the novel vascular graft between the inferior vena cava and the pulmonary artery.

and blood vessels (Figure 5). In some areas, the graft material is encapsulated completely in connective tissue. Mechanical testing of the explanted grafts indicated that the developed new tissue has a high burst pressure that exceeds the limits required for a commercial conduit.

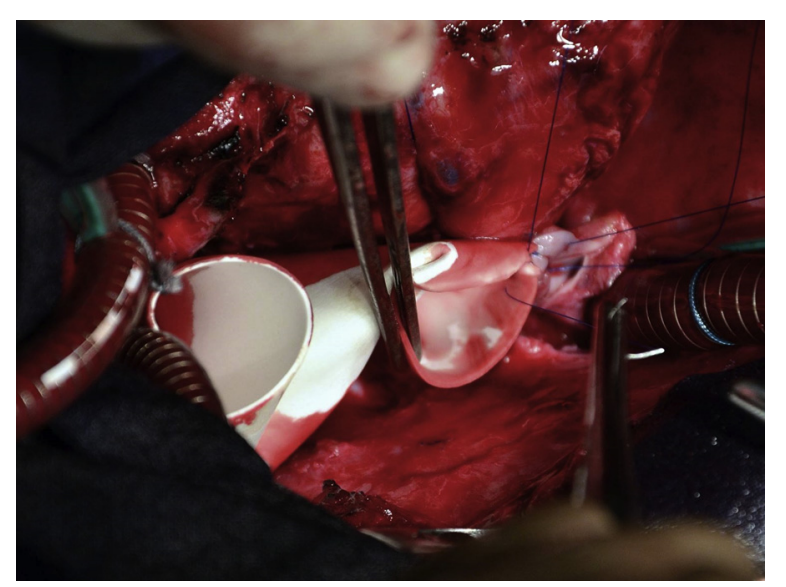

FIGURE 3. Magnetic resonance imaging of the vascular graft at 6 months' follow-up in Patient 1, showing frontal view of graft and 4-dimensional imaging view that demonstrate the patency of the conduit.
Since 1983, 709 operative procedures to realize a Fontan circulation have been performed at the Bakulev Center for Cardiovascular Surgery, including 476 (67\%) extracardiac cavopulmonary conduits with an overall operative mortality of $5.7 \%$. Most of the conduits ( 428 or $90 \%$ ) were made of expanded PTFE (W. L. Gore \& Associates, Inc, Flagstaff, Ariz) with diameters ranging between 14 and $24 \mathrm{~mm}$.

All patients who received this new vascular graft did well at the 12-month follow-up visit. The majority of adverse events were pleural effusions, a well-known complication after a Fontan procedure. The etiology is multifactorial, but there is no prophylactic treatment or special operative strategy to avoid postoperative pleural effusions. ${ }^{23,24}$ Arrhythmias commonly are reported after the modified Fontan procedure, ${ }^{25}$ and in this small series, 2 patients experienced branch bundle block and sick sinus syndrome. These events were both classified as mild events and did not require treatment, although they were not resolved at 1 year after implantation.

No graft-related adverse events were observed during the clinical observation up to 12 months after the graft implantation. One patient experienced a significant decrease in ventricular function. This event was thought to be due to hypercirculation in the collaterals and resolved after interventional occlusion of aortopulmonary collaterals. 
TABLE 2. Postoperative conduit diameter in $\mathbf{m m}(\mathrm{A})$ and maximal blood flow in $\mathrm{cm} / \mathrm{s}(\mathrm{B})$ assessed at 3 levels: SVC, in the middle segment of the graft, and at the level of the IVC

\begin{tabular}{|c|c|c|c|c|c|c|c|c|c|c|c|c|}
\hline \multirow{3}{*}{$\frac{\frac{\text { Pt }}{\text { Level }}}{\text { F/u }}$} & \multicolumn{6}{|c|}{ 01-001 } & \multicolumn{6}{|c|}{ 01-002 } \\
\hline & \multicolumn{2}{|c|}{ SVC } & \multicolumn{2}{|c|}{ Mid } & \multicolumn{2}{|c|}{ IVC } & \multicolumn{2}{|c|}{ SVC } & \multicolumn{2}{|c|}{ Mid } & \multicolumn{2}{|c|}{ IVC } \\
\hline & $12 \mathrm{mo}$ & $24 \mathrm{mo}$ & $12 \mathrm{mo}$ & $24 \mathrm{mo}$ & $12 \mathrm{mo}$ & $24 \mathrm{mo}$ & $12 \mathrm{mo}$ & $24 \mathrm{mo}$ & $12 \mathrm{mo}$ & $24 \mathrm{mo}$ & $12 \mathrm{mo}$ & $24 \mathrm{mo}$ \\
\hline A & 16 & 14 & 20 & 19.7 & 13.2 & 14.5 & 16.5 & 17.4 & 16 & 18 & 19.6 & 19.1 \\
\hline B & 28 & 36 & 25 & 38 & 40 & 14 & 35 & 46 & 32 & 75 & 27 & 43 \\
\hline
\end{tabular}

$S V C$, Superior vena cava; $I V C$, inferior vena cava; $F / U$, follow-up; $n / a$, not available.

This event was reclassified as cardiac failure by the clinical review committee. Otherwise, all significant adverse events reported were resolved at the end of the study.

Echocardiography and 4D flow MRI confirmed a normal function of the conduits with absence of thrombus and blood flow turbulence. The anatomical stability of the grafts was confirmed by the assessment of conduit diameters and wall thickness. No obstruction was seen at the level of the anastomoses or within the conduit up to 12 months after implantation.

Echocardiography, however, was limited to show precise pictures of the proximal and distal portions of the conduit, and it was not possible to estimate the length of the conduit in every patient. As expected, early assessment of the conduit via the use of echocardiography was extremely difficult up to 1-month postimplant, due to postoperative mediastinal changes.

An increasing number of "Fontan patients" are now entering adulthood, and these patients are facing an uncertain future because this procedure remains a palliative treatment. ${ }^{26}$ The most common reason for reoperation is stenosis of the conduit. ${ }^{27,28}$ The most frequently used artificial conduits for the second step of the modified Fontan procedure (total cavopulmonary connection) include PTFE and Dacron. Dabal and colleagues ${ }^{29}$ looked at the long-term results of PTFE conduits used for the Fontan procedure. They reviewed 207 patients over 23 years and reported that a modified Fontan operation using a $16-\mathrm{mm}$ or greater extracardiac conduit combined with a bidirectional Glenn shunt offers excellent long-term survival, freedom from reoperation, and good functional state. ${ }^{29}$

Van Brakel and colleagues ${ }^{30}$ reported recently that the incidence of conduit stenosis in Dacron grafts was extremely high after a Fontan procedure. They retrospectively examined 12 patients who received a Dacron graft and found that $66 \%$ (8 of 12) underwent reoperation because of conduit stenosis. All explanted conduits were replaced with PTFE grafts. The explanted conduits showed tissue deposits on the inner surface. ${ }^{30}$

Conduit size is probably the most significant independent predictor of early conduit-related intervention, most likely resulting from patient outgrowth with regard to the size of the implanted conduit. ${ }^{31}$ Restrepo and colleagues ${ }^{32}$ used MRI to study the flow rates in the conduit after

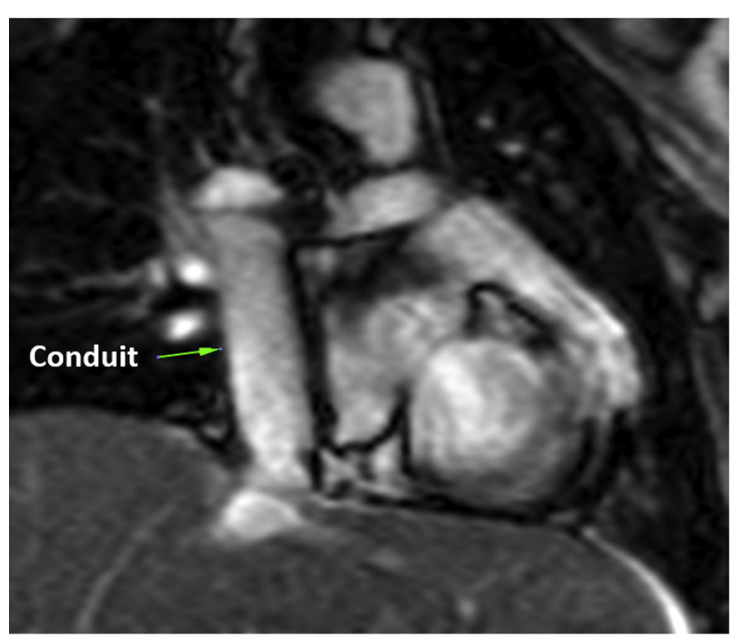

Frontal

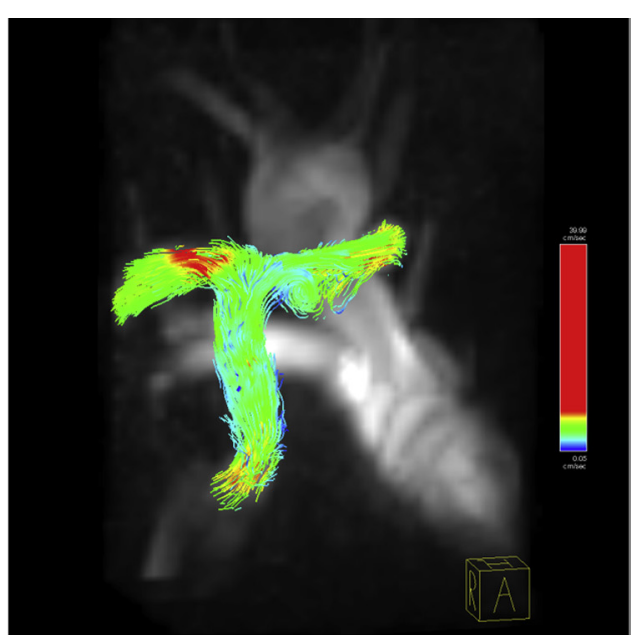

4D-Flow

FIGURE 4. Process of bioabsorption observed with the Xeltis new vascular graft: cell infiltration, tissue formation, graft replacement, and graft removal (up to 53 weeks). Data from preliminary experiments. Adapted from Schoen and colleagues, ${ }^{22}$ with permission. 
TABLE 2. Continued

\begin{tabular}{|c|c|c|c|c|c|c|c|c|c|c|c|c|c|c|c|c|c|}
\hline \multicolumn{6}{|c|}{$01-003$} & \multicolumn{6}{|c|}{ 01-004 } & \multicolumn{6}{|c|}{$01-005$} \\
\hline \multicolumn{2}{|c|}{ SVC } & \multicolumn{2}{|c|}{ Mid } & \multicolumn{2}{|c|}{ IVC } & \multicolumn{2}{|c|}{ SVC } & \multicolumn{2}{|c|}{ Mid } & \multicolumn{2}{|c|}{ IVC } & \multicolumn{2}{|c|}{ SVC } & \multicolumn{2}{|c|}{ Mid } & \multicolumn{2}{|c|}{ IVC } \\
\hline $12 \mathrm{mo}$ & $24 \mathrm{mo}$ & $12 \mathrm{mo}$ & $24 \mathrm{mo}$ & $12 \mathrm{mo}$ & $24 \mathrm{mo}$ & $12 \mathrm{mo}$ & $24 \mathrm{mo}$ & $12 \mathrm{mo}$ & $24 \mathrm{mo}$ & $12 \mathrm{mo}$ & $24 \mathrm{mo}$ & $12 \mathrm{mo}$ & $24 \mathrm{mo}$ & $12 \mathrm{mo}$ & $24 \mathrm{mo}$ & $12 \mathrm{mo}$ & $24 \mathrm{mo}$ \\
\hline 18 & 19.4 & 18 & 19.5 & 18 & 19.7 & 17.9 & 18.5 & 18.2 & 19.7 & 19.7 & 18.6 & $\mathrm{n} / \mathrm{a}$ & 18.3 & $\mathrm{n} / \mathrm{a}$ & 18 & $\mathrm{n} / \mathrm{a}$ & 17.4 \\
\hline 29 & 29 & 13.5 & 25 & 11 & 27 & 21 & 16 & 16 & 25 & 10 & 29 & $\mathrm{n} / \mathrm{a}$ & 31 & $\mathrm{n} / \mathrm{a}$ & 35 & $\mathrm{n} / \mathrm{a}$ & 27 \\
\hline
\end{tabular}

implantation. They showed that the flow rate increased proportionally to the body surface area but that the conduit diameter did not match the somatic growth of vessel; this results in a significant energy loss over time. Oversizing of a conduit is likely to be associated with longer conduit life.

The new vascular graft presented in this paper may provide an original alternative to synthetic grafts: the conduit becomes more biocompatible with time and may reduce the need for reoperation due to outgrowth of the graft. With this in mind, it may provide a better and longer solution for pediatric patients who require a Fontan procedure to treat complex congenital diseases.

\section{CONCLUSION}

This small series confirms that this new conduit is a viable alternative to allografts and synthetically manufactured conduits. Initial clinical experience suggests that this novel technology has the potential to improve cardiac and vascular procedures by reducing permanent implant related complications. Longer follow-up, however,
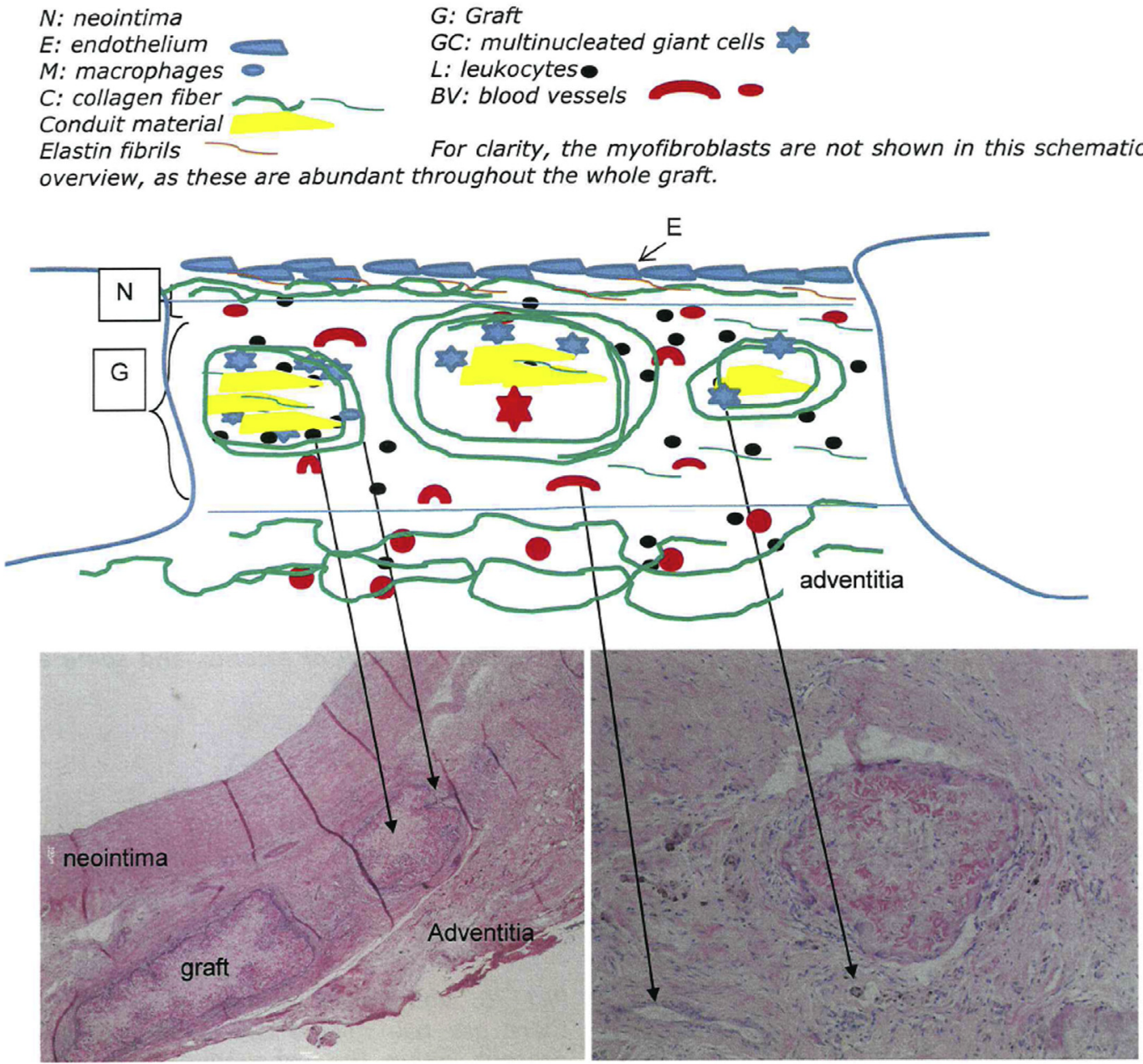

FIGURE 5. Hematoxylin and eosin staining of an explanted graft at 53 weeks postimplant from preclinical studies in animals. 
is needed to fully assess the long-term effectiveness of this bioresorbable vascular graft.

\section{Webcast}

You can watch a Webcast of this AATS meeting presentation by going to: http://webcast.aats.org/2016/Video/Tuesday/ 05-17-16_Ballroom_III_1400_Svanidze-800.mp4.

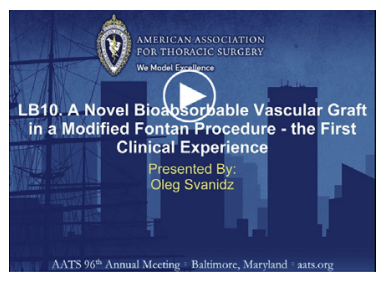

\section{Conflict of Interest Statement}

Martijn Cox and Oleg Svanidze are employed by, and hold shares in, Xeltis AG, the company that has developed the bioabsorbable vascular graft. All other authors have nothing to disclose with regard to commercial support.

\section{References}

1. Costello JM, Pasquali SK, Jacobs JP, He X, Hill KD, Cooper DS, et al. Gestational age at birth and outcomes after neonatal cardiac surgery: an analysis of the Society of Thoracic Surgeons Congenital Heart Surgery Database. Circulation. 2014;129:2511-7.

2. Krexi D, Sheppard MN. Pulmonary hypertensive vascular changes in lungs of patients with sudden unexpected death. Emphasis on congenital heart disease, Eisenmenger syndrome, postoperative deaths and death during pregnancy and postpartum. J Clin Pathol. 2015;68:18-21.

3. Avila P, Mercier LA, Dore A, Marcotte F, Mongeon FP, Ibrahim R, et al. Adult congenital heart disease: a growing epidemic. Can J Cardiol. 2014;30: S410-9.

4. Bobylev D, Breymann T, Boethig D, Haverich A, Ono M. Semilunar valve replacement with decellularized homograft after Damus-KayeStansel anastomosis and Fontan procedure. Ann Thorac Surg. 2014;97: 1792-5.

5. Kiraly L, Dalrymple-Hay MJ, Salmon AP, Keeton BR, Monro JL. The fate of antibiotic sterilized aortic allografts in Fontan circulation: results of the long-term follow-up. Eur J Cardiothorac Surg. 1999;16: 660-2.

6. McElhinney DB, Reddy VM, Hanley FL. Homografts in congenital heart disease: current applications and future directions. Isr J Med Sci. 1996; 32:880-5.

7. Rybicka J, Kowalski M, Rozanski J, Hoffman P. Successful reoperation of the valveless calcified right atrium to right ventricle conduit in an adult patient with tricuspid atresia after Fontan procedure. Eur J Cardiothorac Surg. 2012; 41:e18-20.

8. Grubitzsch H, Laule M, Stangl K, Lembcke A, Sander M, Christ T, et al. Surgical-transcatheter approach for endocarditis of a calcified aortic homograft. J Heart Valve Dis. 2013;22:751-3.

9. Hibino N, He D, Yuan F, Yu JH, Jonas R. Growth of diminutive central pulmonary arteries after right ventricle to pulmonary artery homograft implantation. Ann Thorac Surg. 2014;97:2129-33.

10. Smeets CJ, Bertrand PB, Spadaccio C, Beran M, Verhaert D, Vandervoort PM, et al. Pulmonary homograft endocarditis and aortic autograft failure after Ross procedure: a double stentless bioprosthesis approach. J Heart Valve Dis. 2014; 23:360-3.

11. Joudinaud TM, Baron F, Raffoul R, Pagis B, Vergnat M, Parisot C, et al. Redo aortic root surgery for failure of an aortic homograft is a major technical challenge. Eur J Cardiothorac Surg. 2008;33:989-94.
12. Levy RJ, Qu X, Underwood T, Trachy J, Schoen FJ. Calcification of valved aortic allografts in rats: effects of age, crosslinking, and inhibitors. J Biomed Mater Res. 1995;29:217-26.

13. Lis GJ, Rokita E, Podolec P, Pfitzner R, Dziatkowiak A, Cichocki T. Mineralization and organic phase modifications as contributory factors of accelerated degeneration in homograft aortic valves. J Heart Valve Dis. 2003;12:741-51.

14. Aroca A, Polo L, Perez-Farinos N, Gonzalez AE, Bret M, Aguilar E, et al. Risk factors for surgery of congenital heart disease in adults. Twenty-two years of experience. Who should operate them? Arch Cardiol Mex. 2014; $84: 262-72$.

15. DiBardino DJ, Jacobs JP. Current readings: long-term management of patients undergoing successful pediatric cardiac surgery. Semin Thorac Cardiovasc Surg. 2014;26:132-44.

16. Shinoka T, Breuer C. Tissue-engineered blood vessels in pediatric cardiac surgery. Yale J Biol Med. 2008;81:161-6.

17. Shinoka T. Development of a tissue-engineering vascular graft for use in congenital heart surgery. EBioMedicine. 2014;5:12-3.

18. Sugiura T, Tara S, Nakayama H, Yi T, Lee YU, Shoji T, et al. Fast-degrading bioresorbable arterial vascular graft with high cellular infiltration inhibits calcification of the graft. J Vasc Surg. September 26, 2016 [E-pub ahead of print].

19. Fukunishi T, Best CA, Sugiura T, Shoji T, Yi T, Udelsman B, et al. Tissue-engineered small diameter arterial vascular grafts from cell-free nanofiber PCL/chitosan scaffolds in a sheep model. PLoS One. 2016; 11:e0158555.

20. Lehn JM. Supramolecular Chemistry: Concepts and Perspectives. Weinheim, Germany: Wiley-VCH; 2006.

21. Sijbesma RP, Beijer FH, Brunsveld L, Folmer BJB, Ky Hirschberg JHK, Lange RFM, et al. Reversible polymers formed from self-complementary monomers using quadruple hydrogen bonding. Science. 1997;278:1601-4.

22. Schoen FJ, Cox MAJ, Warnack B, Svanidze O, Bennink G. Vascular remodelling of a novel absorbable polymeric conduit in the ovine pulmonary circulation. Poster presented at the World Biomaterials Conference, Montreal, Canada, May 17-22, 2016.

23. Mascio CE, Austin EH III. Pleural effusions following the Fontan procedure. Curr Opin Pulm Med. 2010;16:362-6.

24. Ugurlucan M, Tuncer EY, Guzelmeric F, Kafali E, Sayin OA, Cine N, et al. Outcomes of the extracardiac Fontan procedure using cardiopulmonary bypass: early results. Heart Surg Forum. 2014;17:E173-7.

25. Sinzobahamvya N, Weber T, Sata S, Haun C, Arenz C, Photiadis J, et al. Quantification of morbidity associated with congenital heart surgery. Thorac Cardiovasc Surg. 2013;61:278-85.

26. d'Udekem Y, Iyengar AJ, Cochrane AD, Grigg LE, Ramsay JM, Wheaton GR, et al. The Fontan procedure. Contemporary techniques have improved longterm outcomes. Circulation. 2007;116:I157-64.

27. Bhat AH, Sahn DJ. Congenital heart disease never goes away, even when it has been 'treated': the adult with congenital heart disease. Curr Opin Pediatr. 2004;16:500-7.

28. Agnoletti G, Bordese R, Corleto A, Gabbarini F, Marini D. Interventional catheterization after total cavopulmonary connection: experience in 68 patients. J Interv Cardiol. 2012;25:622-7.

29. Dabal RJ, Kirklin JK, Kukreja M, Brown RN, Cleveland DC, Eddins MC, et al. The modern Fontan operation shows no increase in mortality out to 20 years: a new paradigm. J Thorac Cardiovasc Surg. 2014; 148:2517-24.

30. Van Brakel TJ, Schoof PH, de Roo F, Nikkels PG, Evens FC, Haas F. High incidence of Dacron conduit stenosis for extracardiac Fontan procedure. J Thorac Cardiovasc Surg. 2014;147:1568-72.

31. Rüffer A. Mid-term experience with the Hancock porcine-valved Dacron conduit for right ventricular outflow tract reconstruction. Eur J Cardiothorac Surg. 2012; 42:988-95.

32. Restrepo M, Tang E, Haggerty CM, Khiabani RH, Mirabella L, Bethel J, et al. Energetic implications of vessel growth and flow changes over time in Fontan patients. Ann Thorac Surg. 2015;99:163-70.

Key Words: conduit, congenital heart disease, tissue engineering, bioabsorbable polymer, pulmonary artery graft Fontan procedure 


\section{Discussion}

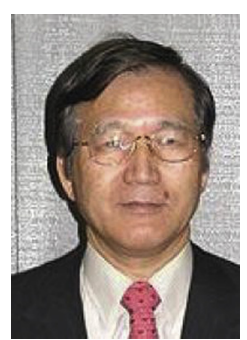

Dr S. Sano (Okayama, Japan). Thank you. Congratulations for your excellent results.

The advantages of tissue-engineered grafts are the potential for growth and to obviate the need for antiplatelet and anticoagulant therapy. Shin'oka and Hibino in the Tokyo Women's Group have implanted tissue-engineered grafts seeded with autologous bone marrow cells. They published their midterm clinical results in JTCVS in 2005 and their long-term results of 25 total cavopulmonary connection grafts in JTCVS in 2010.

Your new graft isn't a seeded graft, so if the result is the same or better than a seeded graft, this is certainly an innovative technique.

I have a few questions. Did you confirm the safety of your materials? Also, do you have animal study data of the histology in the long-term follow-up?

In your manuscript, you mentioned that the preclinical studies in animals were performed with the new graft. You have demonstrated that the vascular material is well tolerated in the initial 18 and has a normal tissue response as soon as it is implanted; however, I couldn't find any preclinical animal study papers published. That's the first question.

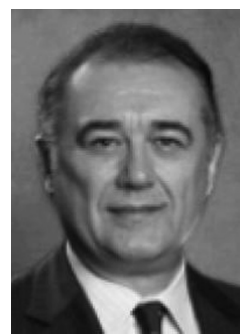

Dr Svanidze. We did quite extensive studies in animals and histology evaluation at different time points starting from 5 days and up to 12 months.

These data are going to be published soon. The manuscript is being prepared. The development of this device started as a classical tissue engineering project with seeded cells on the top of the polymet scaffold. But later on during several preclinical tests, we found that there was not a significant difference between the group with seeded cells and with the pure polymer scaffold. So then, the decision was made to go just with a polymer alone.

Dr Sano. The second question is major complications of the Tokyo Women's series is graft stenosis. From their report, graft stenosis was found in $6,25 \%$ of the patients with a mean follow-up of 6 years. So I think it is too early to say your new graft is superior to a seeded graft with only 12 months of follow-up.

And one of the advantages of tissue engineering graft is obviating the need for antiplatelet and anticoagulant therapy; however, you used the warfarin in 3 patients and aspirin in 2 patients. Could you explain why you used these drugs?

Dr Svanidze. Yes. First of all, the decision to go with the purely polymeric graft was made for practical reason because by using classical tissue engineering with seeded cells, these devices are not very practical for commercial production.
And then regarding the anticoagulation, we didn't anticoagulate our animals at all. But with this study, 3 patients received long-term anticoagulation with warfarin and 2 patients just for 3 months, and this was determined by the policy of the particular departments because those patients were from 2 different departments.

Dr Sano. Thank you. I look forward to hearing about the long-term results of this new graft and also the new valve-to-conduit. Thank you. Congratulations.

Dr Svanidze. Thank you. And we're preparing 2-year data to be submitted to the European Association for Cardio-Thoracic Surgery meeting in Barcelona.

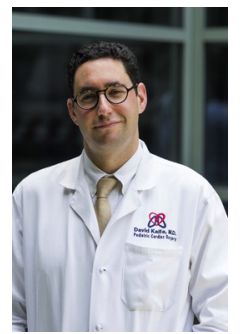

Dr D. Kalfa (New York, NY). Thank you for this presentation and congrats for this work.

Dr Sano just emphasized the need for more preclinical in vitro results. Dr Sano was talking about the histologic in vitro evaluation mainly, but what about the growth potential of this device? And, what about the mechanical properties of this polymer and device, since the controlled loss of mechanical properties is one of the main potential mid- or long-term risks for this kind of tissue engineering devices. Could you please comment on these 2 points?

Dr Svanidze. Of course, the potential of the growth is very important, but we decided to go step by step and take first as a proof of concept just regular adult animal implants and see how the device will perform in those animals.

With the next phase, we are planning to do implantations in the young sheep, in the growing model to see whether this technology will allow the growth.

The other problem here is that the growth rate between the animals and humans are different, and while you will design the device that will be sufficient in terms of the speed of growth for human, it might not work in an animal. So this needs to be taken into consideration as well.

Dr Kalfa. What about the mechanical properties?

Dr Svanidze. Regarding the mechanical properties, we found that implant had slightly higher strength than the native tissue. This was confirmed at several time points of explant of the device. And as I said, at 6 to 8 weeks after surgery, the mechanical property is being taken over by neo-tissue.

Dr Kalfa. Thank you.

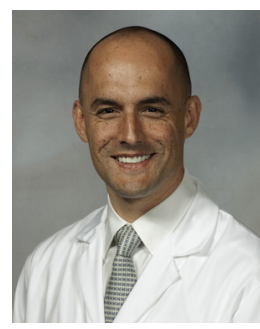

Dr J. Salazar (Jackson, Miss). Just to clarify, when you say stronger than native tissue, you're referring to pulmonary artery tissue, or what are you comparing it to?

Dr Svanidze. Yes, to the pulmonary artery tissue and still keeps the compliance about $15 \%$.

Dr Salazar. And no aspirin was necessary at all? 
Dr Svanidze. No.

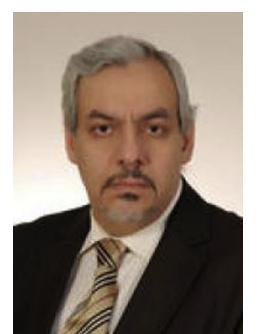

Dr Z. Al-Halees (Riyadh, Saudi Arabia). I presume the implantation in patients with Fontan was without a valve, I mean a valveless conduit. Was it?

Dr Svanidze. No valve. It was a just a vascular graft.

Dr Al-Halees. So clinically you don't know how the valved conduit will function? The valve itself has not been tested in patients for function?

Dr Svanidze. We developed a valved conduit that has been implanted in animals and has shown quite encouraging results. So as I said, it opened the way to start clinical trials later this summer.

Dr Al-Halees. So did you have any histologic evaluation of the valve leaflets within the conduit from these animals?

Dr Svanidze. Yes. The valve leaflets have been, of course, evaluated and showed restoration of the tissue. However, it was slower for the leaflets, and we explained this by differences of mechanical loads and hemodynamic conditions for the leaflets and the wall of the conduit.

Dr Al-Halees. And remained competent and no stenosis?

Dr Svanidze. No stenosis, and it was trivial to mild regurgitation noticed at 6 and 12 months.

Dr Al-Halees. Thank you.

Dr A. Jones (Virginia Beach, Va). I was curious as to the cell types that you were seeing that had infiltrated into the graft.

Dr Svanidze. Usually it starts as a regular inflammatory response with microphages starting to digest a polymer, but because of the unique structure of this matrix, it creates favorable conditions for cells to be developed and fibroblasts taking over later on with deposits of proteins there. And we even found development of elastin, which is quite important for good performance of the leaflets and which keeps compliance of this device.

Dr Jones. Just one last follow-up. Did you notice any transition from your macrophages from an M1 to an M2 phenotype?

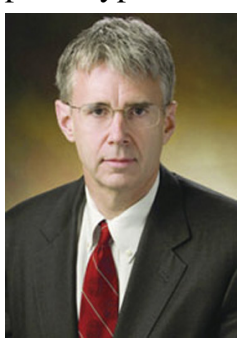

Dr Gaynor (Philadelphia, Pa). I'm sorry, we couldn't understand that.

Dr Jones. Sure. Did you notice that your macrophages transferred or converted from an M1 to an M2 phenotype?

Dr Gaynor. Did macrophages convert from an M1 to an M2 phenotype?

Dr Svanidze. No, I don't think I have this information now.

Dr P. Gruber (Iowa City, Iowa). Have you ever tested this in the systemic circulation?

Dr Svanidze. Yes. This type of conduit has been tested in the descending aorta in sheep, with the similar properties of the polymer, and it performed quite well. Also, the development of the aortic valve has started just a few months ago.

Dr J. Gaynor. When you make the conduits, can they be cut without unraveling? I mean, you don't have to preform them for a particular patient, right? Can you cut it, the length, and tailor it to fit anybody?

Dr Svanidze. Yes. You can cut it fairly easily. It behaves exactly like Gore-Tex, and you don't have to preform it for a particular patient. 